\title{
HOSPITALIDAD, CON Y SIN PAPELES
}

\author{
Hospitality, with and without documents
}

\section{Ana Paula Penchaszadeh ${ }^{*}$}

\begin{abstract}
Resumen. El objetivo de este artículo es vincular el trabajo sobre el archivo de Jacques Derrida con la experiencia de la hospitalidad. Se intentará mostrar que, por un lado, se trata siempre de los papeles, de la legitimidad que éstos otorgan o no tanto a nivel filosófico (deseo de poseer los papeles que autoricen tal o cual decisión interpretativa), como a nivel político ("tener papeles" como el principio básico de todo derecho a tener derechos, de todo derecho a la comunidad). Mas también, por otro lado, se intentará pensar aquello que arruina la idea misma de tener o no tener (papeles), la idea de propiedad, aquello que hace imposible fundar una decisión o identidad en última instancia y, por ende, una soberanía, una frontera. La hospitalidad, la llegada inminente del otro, representa un desafío político y ético para la filosofía: pues no se trata de un saber, sino de una experiencia transformando el sustrato del nos-otros, del ser común.
\end{abstract}

Palabras clave: hospitalidad, archivo, Derrida, migraciones, papeles.

\begin{abstract}
The objective of this article is to link the work on Jacques Derrida's archive to the experience of hospitality. It will seek to show that, on the one hand, it is always about the documents, the legitimacy that these do or do not grant at the philosophical level (desire to possess documents that will authorize one or another interpretative decision), as well as at the political level («being documented» as a basic principle to every right to have rights, to all rights to community). But on the other hand, there is an attempt to think about that which ruins the proper idea of to have or not to have (documents), the idea of property, that which ultimately makes it impossible to construct a decision or identity and, therefore, a sovereignty, a border. Hospitality, the imminent arrival of the other, represents a political and ethical challenge for a philosopher: it is not to do with a knowledge, but an experience transforming the substrate of ourselves/others, the common self.
\end{abstract}

Keywords: hospitality, archive, Derrida, migrations, documents.

* Investigadora del Consejo Nacional de Investigaciones Científicas y Tecnológicas (CONICET) y del Instituto de Investigaciones Gino Germani de la Universidad de Buenos Aires. Buenos Aires, Argentina. 
Ana Paula Penchaszadeh (fuan Pablo Penchassoff)'

"La decisión de la hospitalidad requiere que invente mi propia regla. En este sentido, el lenguaje de la hospitalidad debe ser poético"2.

"Los comportamientos xenófobos y anti-hospitalarios pueden efectivamente analizarse en aquellas personas que tienen dificultades con lo extranjero en ellos, con sus propios fantasmas, mientras que aquellos que tienen el gusto, el talento o el genio de la hospitalidad son aquellos que aceptan la multiplicidad en ellos, que saben tratar con lo extranjero en ellos, bajo múltiples formas" ${ }^{\prime 3}$.

\section{Invitación}

Trasladarse desde Buenos Aires a la bucólica campiña normanda; lograr vencer la distancia (geográfica, económica y burocrática) que me separaba de los archivos de Derrida sobre la hospitalidad ("sí, madame, tenemos varios dossiers con las sesiones de los seminarios, conferencias y manuscritos de Derrida sobre la hospitalidad entre los años 1995 y 1998", me habrían contestado desde el IMEC); permanecer horas y horas encerrada en una vieja Abadía de lustre nuevo intentando comprender la diferencia entre lo que Derrida decidiera publicar y ese "resto" de textos inéditos que engrosan hoy su archivo ${ }^{4}$; pero ante todo, saber que en estas pequeñas minucias mundanas no residiría ni reside el gran problema que amenaza con volver estéril todo trabajo de archivo: mis resistencias respecto de la visita a los archivos de Derrida guardaban y guardan relación con el "mal de archivo" que tan sutilmente definiera éste en su texto homónimo ${ }^{5}$.

En estas páginas intentaré vincular el trabajo sobre el archivo de Derrida con la experiencia de hospitalidad. Intentaré mostrar que, por un lado, se trata siempre de los papeles, de la legitimidad que éstos otorgan o no tanto a nivel filosófico (deseo de poseer los papeles que autoricen tal o cual decisión

1 La hospitalidad se vincula también con el problema de la sustitución, con el cambio de identidad desde el origen. Así, el nombre propio no tiene nada de propio y remite, contiene, las huellas de otros otros que fueron dejados en el camino. El nombre, los nombres de familia, como cifra, son huellas de sobrevivencia (el sobreviviente es el que ha experimentado, en cierta forma, la muerte y lo testifica alimentándose, por siempre, de cierta carroña). Primera substitución: la niña por el niño, se esperaba un niño, pero llegó una niña; el nombre del niño (Juan Pablo) fue traducido al femenino (Ana Paula). Segunda sustitución: para huir de la persecución de judíos en la Rusia revolucionaria del '17, mi familia paterna, oriunda de Bujará (hoy en Uzbekistán), compró pasaportes persas para instalarse en Francia; el apellido se persificó (Penchassoff devino Penchaszadeh).

2 DERRIDA, Jacques. IMEC, 1998, p. 36.

3 Ibidem, p. 40.

4 A mediados del mes de agosto de 2016 realicé, con el apoyo de Patrice Vermeren y en el marco de una investigación postdoctoral en la Université Paris 8, una estadía en el IMEC para trabajar los archivos de Derrida sobre la hospitalidad (1996-1998). Al final de este documento, en el apartado bibliográfico, sistematizo la serie de documentos que analicé entonces.

5 DERRIDA, Jacques. Mal de archivo. 
interpretativa), como a nivel político ("tener papeles" como el principio básico de todo derecho a tener derechos, de todo derecho a la comunidad); mas también intentaré mostrar que se trata de aquello que arruina la idea misma de tener o no tener (papeles), la idea de propiedad, haciendo imposible fundar una decisión o identidad en última instancia y, por ende, una soberanía, una frontera. Por eso: hospitalidad, con y sin papeles.

\section{Visitación}

“(...) del secreto mismo, por definición, no puede haber archivo. El secreto es la ceniza misma del archivo, el lugar donde ni siquiera tiene ya sentido decir «la ceniza misma»o «en la mismísima ceniza». No tiene sentido buscar el secreto de lo que cualquiera ha podido saber" ${ }^{\prime \prime}$.

Derrida nos recuerda que en la raíz de la palabra "archivo" se halla el vocablo arkhé que implica, a la vez, comienzo y mandato, dos principios topológicos vinculados con el origen y la autoridad: un principio ontológico natural o histórico -asociado al lugar del comienzo- y un principio legal o nomológico -ligado al ejercicio de la autoridad, al lugar donde se imparten el orden y las órdenes ${ }^{7}$.

Tranquiliza encontrar (o creer haber encontrado) en el archivo un origen, comienzo o principio físico, histórico y ontológico. Pero resulta menos tranquilizador su sentido nomológico (el arkhé del mandato) que se dirige a aquello sobre lo que se funda todo orden. Según Derrida, esta segunda acepción, que amenaza con perderse en el olvido, se vincula con el arkheion griego, con ese lugar específico donde residen los arcontes, los magistrados superiores que sustentan el poder político y tienen el derecho de hacer y representar la ley. Los arcontes no sólo serían los guardianes de los documentos oficiales, serían también sus hermeneutas e intérpretes:

Confiados en depósito a tales arcontes, estos documentos dicen en efecto la ley: recuerdan la ley y llaman a cumplir la ley. Para estar así guardada, a la jurisdicción de este decir la ley le hacía falta a la vez un guardián y una localización. Ni siquiera en su custodia o en su tradición hermenéutica podían prescindir los archivos de soporte ni residencia. ${ }^{8}$

Derrida se detiene en el cruce de tópos y nómos, en cierta espacialidad donde se cruzan el lugar y la ley que, a su vez, hace de soporte de la autoridad. Este poder arcóntico hace posible la consignación, es decir, la unificación, identificación y clasificación de los signos, su domiciliación y toponomología. No hay autoridad sin esta posibilidad de domiciliar y emplazar físicamente

\footnotetext{
6 Ibidem, p. 106.

Ibidem, p. 10.

8 Ibidem.
} 
la orden, sin una identificación posible del sujeto o los sujetos que imparten las órdenes. Esa función árquica se cruzaría con la verdad patriarcal, con su función archivística de producción violenta de una unidad, de una soberanía.

La consignación tiende a coordinar un solo corpus en un sistema o una sincronía en la que todos los elementos articulan la unidad de una configuración ideal. En un archivo no debe haber una disociación absoluta, una heterogeneidad o un secreto que viniera a separar (secernere) compartimentar, de modo absoluto. ${ }^{9}$

El archivo, el poder arcóntico, hace posible una institucionalización de la ley y de la autoridad autoriza esta ley. Pero también guarda relación con la anarquía, con todo aquello que se encuentra fuera del poder archivístico, con lo reprimido, con aquello que viene a arruinar cada vez todo orden (homogéneo, limpio, impoluto, reservado). Derrida identifica el deseo de orden y control archivístico con la pulsión de muerte: no se trata de una memoria como experiencia viva, interior y espontánea, dice, sino de una pura exterioridad, de un afuera (a salvo del paso del tiempo y de la vida) animado por la técnica de la repetición. Ahora bien, así como todo texto "se deconstruye" a sí mismo, el archivo, ese rejunte de textos e inscripciones, trabaja "siempre y a priori contra sí mismo"10. El mal de archivo guarda relación con la posibilidad siempre abierta de un olvido, con una pulsión de muerte, como agresión y destrucción que constituyen, y al mismo tiempo acechan, todo trabajo arcóntico.

[...] todo archivo, sacaremos de ello algunas consecuencias, es a la vez instituyente y conservador. Revolucionario y tradicional. Archivo económico en este doble sentido: guarda, pone en reserva, ahorra, mas de un modo no natural, es decir, haciendo la ley (nomos) o haciendo respetar la ley. Lo llamábamos, hace poco nomológico. Tiene fuerza de ley, de una ley que es la de la casa (oikos), de la casa como lugar, domicilio, familia, linaje o institución. ${ }^{11}$

Para Derrida, repetición y acontecimiento son lo mismo. La deconstrucción siempre está ya en curso, trabajando sobre las fronteras y los límites supuestamente infranqueables de esa toponomología y esa puesta en orden: una heterogeneidad, una disociación absoluta, un secreto vienen a cercenar el corpus y toda fantasía de unidad/individualidad. En palabras de Derrida, "el orden ya no está asegurado"12; si bien es cierto que hay, desde cierta lógica del cálculo, una política del archivo que instituye toda posibilidad de la res pública como control soberano de "lo sensible" -distinguiendo entre lo apropiado y lo inapropiado, lo privado y lo público, a partir de una cierta economía del

\footnotetext{
9 Ibidem, p. 11.

10 Ibidem, p. 20.

11 Ibidem, p. 21.

12 Ibidem, p. 12.
} 
secreto- y que, por lo tanto, no hay Estado sin archivos prohibidos; no es menos cierto que aquello que funda el poder soberano es, en última instancia, la incondicionalidad y la ausencia de fundamento del orden. El archivo anarchiva: "una represión también archiva aquello cuyo archivo disimula o encripta"13, dice Derrida. El "mal de archivo" es la marca de castración de toda autoridad, es el punto en el que el poder soberano se muestra incapaz de controlar y asir la anarquía democrática, la différance, es ese resto que necesariamente viene a arruinar todo gesto de unidad y de "entente":

[...] nadie ha aclarado mejor que Freud eso que hemos llamado el principio arcóntico del archivo, lo que en el archivo supone no el arkhé originario sino el arkhé nomológico de la ley, de la institución, de la domiciliación, de la filiación. Nadie ha analizado mejor que él, vale decir también deconstruido, la autoridad del principio arcóntico. Nadie ha mostrado mejor que él cómo ese principio arcóntico, es decir, paterno y patriárquico, no se planteaba más que repitiéndose y no (re)aparecía para re-ponerse más que en el parricidio. (Re)aparece en el parricidio reprimido o suprimido, en el nombre del padre como padre muerto. Lo arcóntico es, en el mejor de los casos, la toma de poder del archivo por los hermanos. La igualdad y la libertad de los hermanos. Una cierta idea, vivaz aún, de la democracia. ${ }^{14}$

El ejercicio deconstrutivo consiste en renunciar a la idea misma de unidad, de concepto. El concepto se disloca, "no hace nunca uno consigo mismo"15. Cada palabra nos lega una herencia como tarea, un cierto diálogo imposible con los muertos y los fantasmas, con aquello/aquellos que llegan ${ }^{16}$. Derrida dice que el fantasma no responderá jamás en el porvenir porque ya ha respondido y que la posición del fantasma guarda afinidad con la del psicoanalista ${ }^{17} \mathrm{Como}$ aquel que debe "retirarse hacia esa posición espectral, el lugar del muerto, desde la cual, dejando hablar, hace hablar, no respondiendo nunca más que para callarse, no callando más que para dejar la palabra al paciente, el tiempo de transferir, de interpretar, de trabajar"18. Derrida, y ésta es tal vez la cuestión más preocupante que acecha todo trabajo de archivo, sostiene que lo que se

\footnotetext{
13 Ibidem, p. 73.

14 Ibidem, p. 102.

15 Ibidem, p. 92.

${ }^{16}$ DERRIDA, Jacques. Espectros de Marx, p. 85.

17 Derrida cuenta en su texto que Yerushalmi (primer arconte del psicoanálisis) preguntaba a Freud acerca del orden y del sentido de su legado y que Freud guardó largo tiempo silencio: cuando por fin contestó insistió en que el deseo de controlar el legado y la herencia no era más que la pulsión de muerte que acechaba todo archivo, pues la pulsión de vida estará siempre del lado de lo incalculable, de las lecturas porvenir y de la an-arquía a la que necesariamente estarían sometidos los textos al haberse perdido tanto el autor como el destinario. Y el trabajo de archivo también involucra una pulsión de muerte porque parte del presupuesto de que el fantasma puede responder.

${ }^{18}$ DERRIDA, Mal de..., op. cit., p. 69-70.
} 
encuentra sometido a cierta muerte en el archivo es el porvenir, la venida del otro y el mesianismo. Recordemos que si el gran gesto derridiano consistió en hacer una crítica de toda la metafísica de la presencia, necesariamente su mirada del archivo se dirigirá mas bien a aquello que escapa a la lógica del cálculo archivístico, a aquello que "ya no tiene ninguna relación con el registro de lo que es, con la presencia de lo que es o habrá sido actualmente presente"19. Así, todo gesto de reunión de sí, de soberanía, supone una violencia, una consignación que supone a la vez impresión, supresión, represión ${ }^{20}$.

El archivo se vincula, entonces, con la frontera inestable entre lo público y lo privado, entre aquello que constituye el orden explícito y exotérico (aquello que fuera escrito para ser leído) y el orden secreto y esotérico (aquello que habría sido retirado de la luz pública y que marcaría el límite de lo "apropiado"). La inestabilidad de esta frontera, a su vez, reenvía al problema general de la traducción como traición de aquello que debería permanecer secreto e intraducible:

Singularidad irremplazable de un documento que hay que interpretar, repetir, reproducir, mas en su unicidad original cada vez; un archivo debe ser [...] a la vez ofrecido y hurtado a la traducción, abierto y sustraído a la iteración y a la reproductibilidad técnica. ${ }^{21}$

Nuevamente, acontecimiento y repetición. Según la estructura farmacológica que haría de sustento libidinal y deseante de toda deconstrucción -entendida como compromiso aquí y ahora- padecer el "mal de archivo" es, para Derrida, "arder de pasión", "no tener descanso, interminablemente buscar el archivo ahí donde se nos hurta"22. El archivo anarchiva, sustrae, suprime, reprime. Debe ser pensado así también en el horizonte espectral de la mesianicidad, como un "lugar que da lugar sin ser un lugar" (khôra).

El mal de archivo consiste en cierta nostalgia irreprimible del origen. Ahora bien, este deseo de archivo sólo puede culminar en la experiencia de

\footnotetext{
${ }^{19}$ Ibidem, p. 79.

${ }^{20}$ Un tiempo atrás en Brasil, conocí a un matrimonio ya malavenido que me contó que el único recuerdo que tenía de su fiesta de casamiento era el descarte de fotos que no habían sido seleccionadas para ser copiadas. Según contaban con pesar (tal vez anticipatorio, pues su lazo no estaría destinado a durar mucho más), la casa de fotografía, junto con su selección de fotos, se había incendiado, dejándoles sólo ese resto de fotos que nadie hubiese querido reproducir. Este ejemplo (lógica de la sustitución) resulta esclarecedor de los dilemas comprometidos en el trabajo de archivo: ese supuesto sustrato originario sólo nos habla de un desvío, de una represión, de una contingencia radical. El archivo es un resto; entender esto en su profundidad implica que la hospitalidad incondicional no se mueve en el terreno de la palabra (de los papeles que en el archivo se encuentren), sino en el terreno del silencio, de lo inaparente, de lo espectral: todo trabajo arqueológico se basa en la economía poética del lenguaje y en la ficcionalización actual (verosímil) del origen.

${ }^{21}$ DERRIDA, Mal de..., op. cit., p. 97-98.

22 Ibidem, p. 98.
} 
una sustracción/sustitución desde el origen: el origen es huella, huellas de otros cuyos hacedores (si los hubiere) habrían partido siempre-ya. Para Derrida en la sobrepuja ínsita en el archivo, en el concepto de archivo y en la estructura del concepto en general, es posible entrever que la destrucción anarchivante pertenece al proceso de la archivación y produce aquello mismo que reduce, a veces a cenizas y más allá23. El gesto de unidad y consignación se encuentra acechado tanto por la represión del otro, como por su llegada inmininente:

[...] las Luces por venir deberían pues ordenarnos contar también con la lógica del inconsciente, y por consiguiente, con la idea al menos, no digo con la doctrina, introducida por una revolución psicoanalítica, la cual, por lo demás, no tendría ninguna oportunidad de surgir en la historia, entre otras condiciones, sin esta medicina envenenada, sin el pharmakon de esta inflexible y cruel auto-inmunidad que aquélla denomina a veces "pulsión de muerte" y que no se limita al ser vivo en su forma consciente y representativa. ${ }^{24}$

El trabajo sobre el archivo es obsceno: obliga a salirse de la escena, a tener el coraje de renunciar a la búsqueda de un origen que autorice la propia reflexión (una vuelta de sí sobre sí). Este salirse de la escena, implica que toda decisión de trabajar sobre un archivo es indecidible y compromete una cierta pasividad y heteronomía. Dice Derrida, "la memoria fiel de una singularidad (...) no puede más que entregarse al espectro" ${ }^{25}$. A su vez, habría que preguntarse, teniendo en cuenta la represión que entraña el trabajo de archivo (ese mal de archivo que anarchiva), por qué hemos elegido este archivo y no tantos otros archivos que hablarían de tantas otras cosas. Cuando estoy en Caen, no estoy en París. Sacrifico así otra búsqueda, quizá más incómoda, un diálogo con otros muertos, otros muertos a los que se quiere (iquién quiere?) tal vez conjurar. La decisión es siempre decisión del otro: cuando estoy aquí hablando con este muerto, no estoy allá hablando con otros muertos. Principio básico de hospitalidad y hostilidad: al responder a un otro sacrifico al mismo tiempo a otros otros, la decisión desgarra cada vez el principio de unidad de sí, la decisión me transporta lejos de mí:

[la paradoja de la decisión] así como ella me compromete y ella define mi responsabilidad, mi decisión es una decisión del otro en mí. Para que haya decisión (si la hubiere), es necesario que ella desgarre el curso del tiempo, que sea irruptiva. Ella no sería el simple desarrollo de aquello de lo que soy capaz, una simple explicitación de mis potencialidades. La decisión es tan radical que ella no puede más que venir de otro en mí. Soy libre y por tanto soy pasivo en relación a esta decisión que me desgarra, que interrumpe mi propia continuidad. La paradoja es que una vez surgida la decisión, somos

\footnotetext{
${ }^{23}$ Ibidem, p. 101.

${ }^{24}$ DERRIDA, Espectros ..., op. cit., p. 187.

${ }^{25}$ DERRIDA, Mal de..., op. cit., p. 105-106.
} 
a la vez fundamentalmente responsables y no responsables: la decisión es tomada. De ahí la idea que es de otro. Al mismo tiempo, dar de si en la hospitalidad es decidir exponerse, ofrecerse, darse, pero esta decisión no puede permanecer mía porque si sigo siendo dueño de esta decisión, no doy nada. La decisión me transporta, me lleva lejos de mí. ${ }^{26}$

La herencia como tarea, es un trabajo de los vivos, pues el muerto ya habló. Es decir, habla pero no responde. El trabajo sobre el archivo, como trabajo de traducción debe pensar lo inaparente, los silencios, leer entre líneas y, por sobre todas las cosas, renunciar a domiciliar la experiencia de hospitalidad -sustraída como está de la toda lógica del saber- en la cifra del concepto. iShame on me, vergüenza, vergüenza! ¿Cómo pude tan si quiera pensar que el trabajo sobre el archivo de Derrida podía autorizar esta lectura? Soy el porvenir, esa destinataria imprevista que viene a sentenciar nuevamente la muerte del autor, de Derrida como autor: ihe aquí la hospitalidad del texto, más allá del archivo, que resume todo gesto de hospitalidad y hostilidad! Vengo a recordar que no hay hospitalidad sin hostilidad y isufro, sufro porque bien me gustaría que todo discurra en el encuentro con un otro que no esta siempre-ya en guerra consigo mismo, que es individuo y sujeto, no singularidad transida por otros otros recordándome que la decisión debe desgarrarlo a él y a mí! ${ }^{27}$

El legado de Derrida es una tarea que arruina todo deseo de origen y autorización. Nunca estuve más sola frente a la decisión de escribir e intervenir y, sin embargo, nunca estuve más habitada por otros otros: aquí y ahora es la llamada, aquí y ahora se impone cierta renuncia a los papeles: hospitalidad más allá del saber. La filosofía infinitamente remitida a la autoridad de los padres muertos y los Estados en las fronteras, cada uno desde su archivo, repiten sin cesar que es preciso tener papeles. Pero en esta repetición mecánica, de a ratos, es posible experimentar variaciones. Vuelvo así al epígrafe de este apartado y en especial a la última frase que tal vez podía resultar incomprensible al comienzo (o incluso fruto de un error de traducción): "No tiene sentido buscar el secreto de lo que cualquiera ha podido saber". Todos sabemos que la llegada masiva de personas, las grandes migraciones, son sentidas, pensadas y codificadas por las sociedades anfitrionas como desastres naturales que les acaecen poniendo riesgo el orden común, la paz social, las fronteras. El sentido común insiste por doquier en señalar la existencia de un vínculo profundo entre migraciones y anarquía. ¿Qué nos enseña la reflexión de Derrida sobre el archivo? Enseña que si existe una afinidad entre migraciones y anarquía ésta debe buscarse en la conmoción del fundamento de la autoridad que se produce con la llegada

\footnotetext{
${ }^{26}$ DERRIDA, IMEC, 1998, p. 50.

27 “(...) la subjetividad en sí misma es principio hospitalidad; la intencionalidad o la conciencia es originariamente hospitalaria" (DERRIDA, Jacques. IMEC, Seminario Hostipitalidad, sesión del 21/11/1996).
} 
del otro, del migrante. Existe una afinidad entre el problema general del archivo (de la autoridad, de los papeles, de la autoridad que da los papeles, de los papeles que autorizan) y la hospitalidad: la llegada del otro hace imposible la consignación, la unificación, la identificación y la clasificación, pues la comunidad (común-unidad) se pone en movimiento. Las migraciones se hallan por fuera del poder archivístico, arruinan cada vez el orden homogéneo, limpio, impoluto, de las partes de la comunidad: la comunidad política excede a la comunidad nacional, el ciudadano es mucho más que el nacional y el tiempo sólo tiene que transcurrir para que aquello que sucedió a nivel espacial (la partida/la llegada) se traduzca en términos políticos. Las migraciones tienen el poder de corroer la fantasía de unidad que se encuentra a la base de toda comunidad (como-unidad): las migraciones introducen la anarquía democrática, representan ese "resto" que interpela el orden desde adentro/afuera.

Según el principio de hospitalidad, que está a la base de la democracia por venir -como aquella que hace lugar a cualquiera más allá de todo cálculo y deber- la experiencia de acogida incondicional del otro sólo puede tener lugar (y tiene lugar, de hecho, cada vez) como transgresión de la regla y renuncia a todo pedido de papeles.

\section{Llegada}

"La hospitalidad es una palabra latina que se deja parasitar por su contrario, la hostilidad, por un huésped indeseable albergado por ella"28.

"[...] no podemos mas que desear a la vez guardar y perder el papel, un papel protector y prometido a su retiro. [...] El papel protege exponiendo, alienando y, por lo tanto, amenazando con retirar eso que él está, de una cierta manera, siempre en proceso de hacer" ${ }^{\prime \prime 2}$.

Hablaré aquí de los papeles que encontré en el archivo de Derrida, mas también hablaré de un Derrida sin papeles, de un Derrida no autorizado, indigno. La trama que aquí propongo, tiene un hilo dorado que la atraviesa: las reflexiones de Derrida sobre la hospitalidad. Pero hay una trama mayor tejida de sobre la factualidad de la movilidad humana, de las migraciones, aquí y ahora; una trama que quiere responder al otro/la otra que yace en el fondo del Mediterráneo, que se mueve en las entrañas de "La bestia", que sigue a los "coyotes" en el desierto, que hace de "mula" en las fronteras, que se amontona con otros muertos en fosas comunes, que llega de todas maneras traspasando muros. Esta trama quiere responder al migrante (y también a las migrantes que son las más en estas comunidades en movimiento) que es rechazado, perseguido, controlado, encerrado, violado, utilizado, maltratado, discriminado, silenciado $y$, finalmente, expulsado por no tener papeles o por

\footnotetext{
${ }^{28}$ DERRIDA, IMEC, 1998, p. 21.

${ }^{29}$ DERRIDA, Jacques. Papel máquina, p. 263.
} 
tener los papeles equivocados. No se trata aquí de Derrida, sino del otro, del migrante, de su partida, de su llegada efectiva e inminente, arruinando por doquier el cálculo soberano (la llegada del otro transforma la constelación social que define el nos-otros). Se trata del pasaje de fronteras, de un ser-Relación, como diría Édouard Glissant, que está en el transcurso contingente y vivo de ser en un espacio/tiempo disjunto y desquiciado.

Hablaré aquí del peregrinar, del viaje, de las migraciones como puesta en cuestión del fundamento atávico de la comunidad: la identidad, la posibilidad misma de figurar una frontera entre un adentro y una afuera, está puesta en cuestión ${ }^{30}$. Asistimos al pasaje de la figura del extranjero (categoría fija definida otrora por el anfitrión en función de su no pertenencia a la comunidad de acogida) a la figura del migrante (categoría definida, autodefinida, por un movimiento continuo entre comunidades políticas, ni aquí ni allá, aquí y allá al mismo tiempo). Y hablaré de todo esto como migrante, pues este texto (como todo texto) es autobiográfico: soy esa que ha vuelto a Francia como migrante nacional a recordar que la identidad se construye sobre la base de una ficcionalización del origen y también (ipor qué no?) de un cierto deseo de identidad. Soy la fragua del tiempo, la otra que se tomó su revancha en el texto de la ley francesa que instituye el derecho de sangre (ius sanguinis): soy ese resto que define también - de lejos, hoy, de manera inquietante- la comunidad política francesa ${ }^{31}$. Sin ejercicio, tengo una ciudadanía que les fuera hurtada, por distintos motivos, a mi madre y a mi padre. No hay nada de descarnado en estas páginas, se trata aquí de una reflexión filosófica al servicio de los dilemas de la identidad en singular y de las hospitalidades en plural.

Para avanzar sobre una trama mayor, es preciso detenerse en la espinosa cuestión del "problema actual de las migraciones". Para empezar, tengo un problema con el problema: las palabras son portadoras de un sentido común que debe ser deconstruído y desnaturalizado. Las migraciones no siempre fueron concebidas como un problema y de hecho fueron en muchos casos (y son, aunque en todos lados y por todos los medios intenten convencernos de lo contrario) grandes soluciones para las comunidades de acogida ${ }^{32}$. También

${ }^{30}$ En su último y fascinante libro, La condition cosmopolite, Michel Agier sostiene es preciso pensar el carácter situacional (incierto, ambiguo, incompleto e indeterminado) de las fronteras y de los sujetos 'en proceso de hacerse' (AGIER, Michel. La condition cosmopolite, p. 7-8). Por eso me refiero a migrantes y no a migrados, pues no hay nada del orden de la necesidad, de la estabilidad ni del hecho consumado en esta figura.

${ }^{31}$ Dice Derrida en el Monoligüismo del otro: “Una ciudadanía, por esencia, no crece así como así. No es natural. Pero su artificio y su precariedad aparecen con más claridad, como el relámpago de una revelación privilegiada, cuando la ciudadanía se inscribe en la memoria de una adquisición reciente" (DERRIDA, Jacques. Monolingüismo del otro, p. 29).

32 Alejandro Grimson en "Doce equívocos sobre las migraciones" sostiene que es un error "Suponer que 'mucha gente' implica 'problemas más grandes'" (GRIMSON, Alejandro. Doce equívocos sobre las migraciones, p. 36). 
es problemática la supuesta "actualidad" del problema migratorio ${ }^{33}$. En la entrevista "Deconstruir la actualidad", Derrida explica que la actualidad nunca está dada y que la "realidad" a la que refiere tiene siempre una "hechura ficcional" a la que urge una contrainterpretación vigilante ${ }^{34}$.

[...] la actualidad, precisamente, está hecha: para saber de qué está hecha, no es menos preciso saber que lo está. No está dada sino activamente producida, cribada, utilizada y performativamente interpretada por numerosos dispositivos ficticios o artificiales, jerarquizadores y selectivos, siempre al servicio de fuerzas e intereses que los "sujetos" y los agentes (productores y consumidores de actualidad -a veces también son "filósofos" y siempre intérpretes) nunca perciben lo suficiente. ${ }^{35}$

Hay una artefactualidad (una hechura de la realidad) etnocéntrica en la mirada de las migraciones. Veamos un ejemplo "actual": hacia mediados de 2015, cuando Europa ya insistía machaconamente en el carácter inédito de la crisis de refugiados que asolaba sus costas y fronteras, 300.000 refugiados ponían cuerpo a este 'acontecimiento'. Pero, este número (descontextualizado, "icientos de miles!" rezaban las primeras planas de los grandes diarios del mundo) invisibilizaba a los más de 4 millones los refugiados que ya habían sido recibidos (sin cobertura mediática) por los países limítrofes a Siria a lo largo de cinco años de conflicto. El acontecimiento no puede reducirse a lo actual, a aquello que se nos presenta: no alcanza con que algo acontezca para que haya acontecimiento. El filósofo deconstructor debe poder pensar el carácter inaparente del acontecimiento como aquello que irrumpe y llega más allá de todo cálculo y saber. Ahí donde se insiste en que hay acontecimiento, es preciso mostrar la repetición; ahí donde se insiste en que sólo hay repetición, es preciso pensar el acontecimiento: la deconstrucción busca desarmar la coartada del amo, mostrando cómo el otro llega cada vez para arruinar su cuenta. Nada comprenderemos de las implicancias políticas y éticas de las migraciones si no entendemos que el otro llega (ha llegado y seguirá llegando) de todas maneras.

[...] la hospitalidad no es un concepto que pueda prestarse a un saber objetivo. Es mas bien una experiencia intencional que debe darse (y de hecho se da siempre y en última instancia) más allá del saber: implica recibir a un otro, extranjero, del que nada se sabe. ${ }^{36}$

Una primera inscripción que llamó mi atención, a penas me hice de los textos que componen las sesiones del seminario dictado por Derrida entre 1996

\footnotetext{
${ }^{33}$ Grimson define esta compulsión de presentar los procesos de movilidad contemporánea como acontecimientos inéditos -como la "Era de las migraciones" - esconde tanto un eurocentrismo como un "cronocentrismo" (Ibidem, p. 35-36).

${ }^{34}$ DERRIDA, Jacques. Deconstruir la actualidad, edición digital.

35 Ibidem.

${ }^{36}$ DERRIDA, IMEC, 1998, p. 37.
} 
y 1997 en la EHESS, es que este seminario no se titulaba sin mas "L’hospitalité" (la hospitalidad), sino "L'hostipitalité" (la hostipitalidad) ${ }^{37}$. Esta adición de dos letras (ti) resulta fundamental porque marca el punto en el que esta palabra o cifra "hospitalidad" reprime algo de sí -su sentido político, vinculado con el origen violento de toda autoposición y soberanía- y deviene un concepto ético puro (desvinculado, en apariencia, de toda reflexión teórico-política). En esta ambivalencia introducida por Derrida en la hospitalidad (que alojaría al mismo tiempo la hospitalidad y la hostilidad) habría residido y reside mi particular interés en su pensamiento para deconstruir/desnaturalizar aquello que definí en mi libro Política y Hospitalidad ${ }^{38}$ como la matriz sacrificial de Occidente y cuyo arcano sería el extranjero como sustento de todo poder soberano: no hay identidad sin diferencia, no hay principio de cierre de sí sin extrañamiento, no hay frontera sin extranjeros.

No existe hospitalidad, en el sentido clásico, sin soberanía del sí mismo sobre el propio hogar, pero como tampoco hay hospitalidad sin finitud, la soberanía sólo puede ejercerse filtrando, escogiendo, por lo tanto excluyendo y ejerciendo violencia. ${ }^{39}$

En la confluencia de hospitalidad/hostilidad -acogida y rechazo, entre el deber ético absoluto y el cálculo político, cada vez y al mismo tiempo los dos polos sin posibilidad de dialectización ni superación- se encontraría a mi entender la originalidad de la propuesta derridiana: el amo no tiene nada que le sea propio, la hospitalidad se juega en el terreno de la ex-apropiación. Derrida permite deconstruir/desnaturalizar las hipótesis realistas y conservadoras (aprehendidas de forma magistral por Carl Schmitt en El concepto de lo político) que sustentan todo pensamiento político posfundacional a partir de una denuncia del pathos soberano que la paradoja de la hostipitalidad desnuda:

Para pensar el ser sí mismo, y no solamente el ser en su casa (en sí), hay que partir de esta mediación por la hospitalidad. La cuestión de la hospitalidad es también la cuestión de la ipseidad, de aquello que quiere decir la identidad de sí. [...] La cuestión de la hospitalidad reenvía a la cuestión del Mismo, a la del sí mismo. O en otras palabras, no es posible constituirse a sí mismo, como sujeto, como ciudadano, como sujeto parlante, etc., sin que la experiencia de la hospitalidad haya comenzado ya plenamente. ${ }^{40}$

\footnotetext{
${ }^{37}$ En la selección de sesiones de este seminario que fueron publicadas, Derrida y Anne Douffourmantelle optaron por el título La hospitalidad a pesar del énfasis claro del libro en la confusión de hospitalidad y hostilidad: (...) nos hemos planteado una cierta cantidad de cuestiones - a partir pero también a propósito de las interpretaciones de Benveniste, principalmente a partir de las dos derivaciones latinas: el extranjero (hostis), reicibido como huésped (hôte) o como enemigo. Hospitalidad, hostilidad, hostipitalidad. (DERRIDA, Jacques, DUFOURMANTELLE, Anne. La hospitalidad, p. 49).

38 PENCHASZADEH, Ana Paula. Política y Hospitalidad.

${ }^{39}$ DERRIDA, DUFOURMANTELLE, op. cit., p. 59.

${ }^{40}$ DERRIDA, IMEC, 1998, p. 51.
} 
Derrida sostiene que es preciso hacer una diferencia sin oposición entre: por un lado, el deber de hospitalidad incondicional de una hospitalidad infinita, pura, espontánea, donadora y absoluta, sin deber ni deuda; y, por otro lado, una hospitalidad condicional, reglada, limitada, controlada por un derecho y una política. En esta tensión no dialectizable entre una ética de la hospitalidad y una política de la hospitalidad, en este hiato, residiría la posibilidad de otra palabra, de "una decisión y una responsabilidad que deben ser tomadas sin el resguardo de una fundación ontológica" ${ }^{\prime 1}$. Así, no hay hospitalidad sin hostilidad, pero tampoco sin transgresión ni principio de ruina de todo gesto soberano.

Sin este hiato, que no es la ausencia de reglas, sino necesidad de un salto en el instante de la decisión ética, jurídica o política, tendríamos sólo que poner en marcha un programa de acción. Nada más irresponsable y más

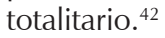

La hospitalidad -como la acogida del otro en el espacio privado- y la inmigración -como la llegada en masa de extranjeros a los que es preciso recibir en "nuestra" sociedad entrañando problemas económicos y políticosno pueden diferenciarse, aun cuando la pureza ética de la hospitalidad no pueda jamás traducirse en el cuerpo de las leyes ${ }^{43}$. Toda experiencia de hospitalidad comporta en realidad una transgresión de la regla y debe darse, en última instancia, como desobediencia civil: pues las leyes que dan forma al derecho de hospitalidad, no pueden más que traicionar la Ley incondicional de hospitalidad inspirada en los derechos humanos y en la dignidad incuestionable de las personas (con independencia de su lugar nacimiento). El derecho de hospitalidad puede faltar (y normalmente falta) a la Justicia, pero sólo podemos tener registro de esta falta porque guardamos siempre el registro de una hospitalidad sin condición.

Las situaciones de pura hospitalidad comportan una tragedia interna. El pasaje al derecho, a la política, y al tercero, constituye, de una cierta manera, una suerte de caída pero, al mismo tiempo, sólo este pasaje que garantiza la efectividad de la hospitalidad. Aparece aquí una aporía política que reclama una responsabilidad a ser tomada, no entre una hospitalidad pura y una hospitalidad condicional, sino al interior de la hospitalidad condicional de manera que ésta sea la mejor posible. La responsabilidad consiste en dar la mejor condicionalidad, la mejor ley posible a una hospitalidad que querríamos tan grande como posible. ${ }^{44}$

La invención política se mueve alternadamente entre el silencio de la hospitalidad incondicional, y la palabra y las leyes que buscan condicionar y

\footnotetext{
${ }^{41}$ DERRIDA, Jacques. IMEC, Seminario Hostipitalidad, sesión 15/11/1996.

${ }^{42}$ DERRIDA, Jacques. IMEC, 1996.

${ }^{43}$ DERRIDA, IMEC, 1998, p. 27.

${ }^{44}$ Ibidem, p. 30.
} 
regular la llegada. Como "el otro llega de todas maneras"45, Derrida prefiere hablar de poéticas de la hospitalidad y no de políticas, pues la decisión de hospitalidad debe implicar la invención de una regla y no debe estar dictada por la aplicación mecánica de una ley: ¿̇o acaso es los papeles son más importantes que las personas? Una traducción justa del entramado jurídico soberano sólo puede ser transgresora, pues sino no habría acogida de aquél o aquella que llega (no del invitado sino del visitante inesperado). No hay acontecimiento sin hospitalidad, no hay hospitalidad sin una justicia que suspenda el derecho para hacer lugar al otro que llega. Así, al mismo tiempo que muchos Estados europeos refuerzan sus fronteras y levantan muros, una parte de la sociedad civil transgrede la ley y reza "iBienvenidos refugiados sirios!".

La hospitalidad compromete, cada vez, la economía poética del lenguaje: no hay democracia sin literatura, sin una ficcionalización del origen que haga lugar a la singularidad del otro en el orden del cálculo. Así, de a ratos es mejor no tener papeles, perderlos y tirarlos: para muchos migrantes solicitantes de refugio, por ejemplo, la construcción de historias verosímiles a la medida de las expectativas variables y relativamente informadas de los Estados anfitriones -es decir, la puesta en práctica de un proceso de identificación creativo, haciendo uso de la economía poética del lenguaje- es muchas veces la única vía para obtener una protección internacional (mostrando que no alcanza simplemente con la realidad del sufrimiento, que el pedido de asilo no es un performativo sino simplemente una ficcionalización que habilita o no una escucha y, finalmente, una palabra que abre puertas: "quédate"). Acá tal vez convenga hablar de la sustitución siempre posible desde el origen y en el origen de lo irremplazable. En este sentido, el arte pareciera estar en mejores condiciones que las ciencias humanas para captar los procesos de subjetivación que desvelan al soberano: "cualquier radicalmente otro es cualquier radicalmente otro", perder los papeles (no tenerlos, quemarlos incluso en el papel del propio cuerpo como soporte de la identidad a través de la borradura de las huellas dactilares), mostraría aquello que la movilidad pone en jaque: la posibilidad de identificación y la domicialición del sujeto ${ }^{46}$. El movimiento, propio de la condición migrante, hace imposible toda comunicación soberana del orden y las órdenes: principio radical y anárquico de la democracia que el migrante puede volver literatura y oportunidad, pues "cualquier radicalmente otro es cualquier radicalmente otro", con o sin papeles, marcando el tiempo de la hospitalidad como acontecimiento en el corazón de una democracia digna de este nombre.

45 Ibidem, p. 39.

${ }^{46}$ Tanto la novela Tea-Bag de Henning Mankell, como el documental Figures de guerre de Sylvain George (2010), son un buen ejemplo de cómo el arte permite sondear los dilemas profundos de la identidad en el contexto de la movilidad humana hoy. 


\section{Comunidades (como unidades) de papel}

Aquí y allá los distintos soberanos reclamarán los papeles. En las instituciones académicas nada podrá decirse ni escribirse sin una debida fundamentación, es decir, sin una remisión clara a la palabra de los padres muertos, a sus papeles y archivos. A su vez, en las comunidades políticas particulares nada podrá hacerse de manera legal y formal sin los papeles que los propios Estados soberanos están en condiciones de dar y, al mismo tiempo, negar, retirar, sustraer, quemar. Vivimos en culturas del papel $-y$, por lo tanto, de papel- con todas las ambivalencias y precariedades que esto supone. El soporte papel sobre el cual se despliega la escritura (con independencia de su sustrato mundano, dígase piedra, papiro, tabla, cuerpo, etc.) permite trascender el tiempo (conjurar la muerte, pues el texto se independiza de su autor y lo trasciende) y el espacio (los papeles son el sustrato de identidad que permite acreditar, aquí y allá, que "tal persona es tal persona"); y, por sobre todas las cosas, la escritura permite crear una distancia reflexiva que habilita, a su vez, un despertar de la consciencia (la justicia despunta en la deconstrucción siempre posible de las capas textuales del derecho).

La escritura, que no puede más que plasmarse en un sustrato externo frágil y, por lo tanto, sujeto a corrupción, degradación y desaparición-, guarda una relación íntima y profunda con la política, con las capas textuales sensibles que permiten la construcción (y, por lo tanto, la deconstrucción) de un "mundo de las cosas", un refugio para generaciones y generaciones de seres mortales ${ }^{47}$; al punto que la identidad de la persona (como sujeto jurídico y de derechos) en el mundo del cálculo soberano, pareciera depender exclusivamente de un papel (de algo, una cosa, que puede perderse, dañarse, robarse, sustraerse, quemarse).

Ahora bien, hay otros papeles, esos sobre los cuales se plasman los derechos humanos, por ejemplo, textos que dicen que las personas son más importantes que los papeles. Muchos Estados soberanos se han comprometido con otros Estados soberanos, han adscripto y firmado otros papeles que protegen excepcionalmente la vida con independencia de los papeles que puedan acreditarla. El ejercicio de la hospitalidad incondicional, la hospitalidad como experiencia, tiene una de sus bases en los derechos humanos, es decir, en otros papeles a los que eventualmente también se puede acudir en nombre de la dignidad humana. Vemos así que si bien se trata siempre de los papeles, la justicia (si la hubiere) sólo puede acontecer como ejercicio político y ético vigilante y transgresor que hace lugar al otro en los pliegues textuales que sustentan la vida-con-otros.

\footnotetext{
47 Hannah Arendt define este mundo de las cosas, creado por el hombre para darle refugio y estabilidad a su existencia mortal, como "mundaneidad" (ARENDT, Hannah. La condición humana, p. 184-191).
} 
El pasaje de fronteras, la puesta en cuestión radical del poder soberano de extrañar, detener y expulsar a personas, debe partir del mal de archivo que aqueja a toda autoridad: no hay ningún papel que sustente, en el última instancia, el poder de los Estados-Nación sobre el territorio que reclaman como suyo. El Estado-Nación es el primero en carecer de un fundamento y, por lo tanto, se halla siempre "flojo de papeles". La obsesión por los papeles, que marca el pulso del ejercicio soberano sobre las fronteras, tiene por función, exigir aquello que sólo él puede dar y que a su vez jamás podrá darse a sí mismo: en el origen estará siempre el otro arruinando de antemano todo intento de unificación y consignación. La hospitalidad es el mal de archivo que da lugar a aquello que se intentó excluir, la llegada del otro/el invitado inesperado que pone en movimiento la democracia por venir.

\section{Bibliografía}

AGIER, Michel. La raison cosmopolite. Paris: La découverte, 2013.

ARENDT, Hannah. La condición humana. Barcelona: Paidós, 1996.

DERRIDA, Jacques. Entrevista Deconstruir la actualidad. Realizada por Douailler, S., Malet, E., de Peretti, C., Sohm, B., Vermeren. Revista Ojo Mocho, n. 5, primavera 1994. Disponible en: <http://www.feeye.uncu.edu.ar/web/epistemologia/ Lineadetiempo/Documentos/Derrida/artefactualidades.htm > .

DERRIDA, Jacques. Espectros de Marx. El estado de la deuda y la nueva Internacional. Valladolid: Trotta, 1995.

DERRIDA, Jacques. Mal de archivo. Buenos Aires: Trotta, 1997.

DERRIDA, Jacques. El monolingüismo del otro. Buenos Aires: Manantial, 1997.

DERRIDA, Jacques. Papier Machine. Paris: Galilée, 2001.

DERRIDA, Jacques. Canallas. Buenos Aires: Trotta, 2005.

DERRIDA, Jacques; DUFOURMANTELLE, Anne. La hospitalidad. Buenos Aires: La Flor, 2000.

GRIMSON, Alejandro. Doce equívocos sobre las migraciones. Revista Nueva Sociedad, n. 233, mayo-junio 2011, p. 34-43.

MANKELL, Henning. Tea-Bag. Buenos Aires: Tusquest, 2013.

PENCHASZADEH, Ana Paula. Política y hospitalidad. Disquisiciones urgentes sobre la figura del extranjero. Buenos Aires: Eudeba, 2014.

\section{Documentos del Archivo de Derrida relevados en el Institut Mémoires de l'édition contemporaine (IMEC) en agosto 2016 :}

DERRIDA, Jacques (1996, IMEC), conferencia «Le mot d'accueil. Anachronies - entre étique et politique» pronunciada el 5 de diciembre en la apertura de un Coloquio en el Collège Interntational de Philosophie, Institut Mémoires de I'édition contemporaine, Caen, France.

DERRIDA, Jacques (1998, IMEC), galeras del libro Une hospitalité à l'infini con 
notas de Derrida Autour de Jacques Derrida. Manifeste pour I'Hospitalité, Mohammed Seffahi (dir.) publicado por Editions Paroles d'aube, Grigny, 1999, Institut Mémoires de l'édition contemporaine, Caen, France.

DERRIDA, Jacques (1999, IMEC), galeras del libro Les lois de l'hospitalité con notas de Derrida, Ed. L’Or du Temps, Túnez, transcripción de una Conferencia dictada en la Cátedra UNESCO en 1998, Institut Mémoires de l'édition contemporaine, Caen, France.

DERRIDA, Jacques (15/11/96, IMEC) Séance du 15 novembre 1996, Seminaire L’hostipitalité (EHESS) Institut Mémoires de l'édition contemporaine, Caen, France.

DERRIDA, Jacques (21/11/96, IMEC) Séance du 21 novembre 1996, Seminaire L’hostipitalité (EHESS) Institut Mémoires de l'édition contemporaine, Caen, France. DERRIDA, Jacques (18/12/96, IMEC) Séance du 18 décembre 1996, Seminaire L'hostipitalité (EHESS) Institut Mémoires de l'édition contemporaine, Caen, France. DERRIDA, Jacques (12/03/97, IMEC) Séance du 12 mars 1997, Seminaire L’hostipitalité (EHESS) Institut Mémoires de l'édition contemporaine, Caen, France.

DERRIDA, Jacques (AR 7/05/97, IMEC) Séance du 7 mai 1997, Seminaire L’hostipitalité (EHESS), Institut Mémoires de l'édition contemporaine, Caen, France.

ANEXO

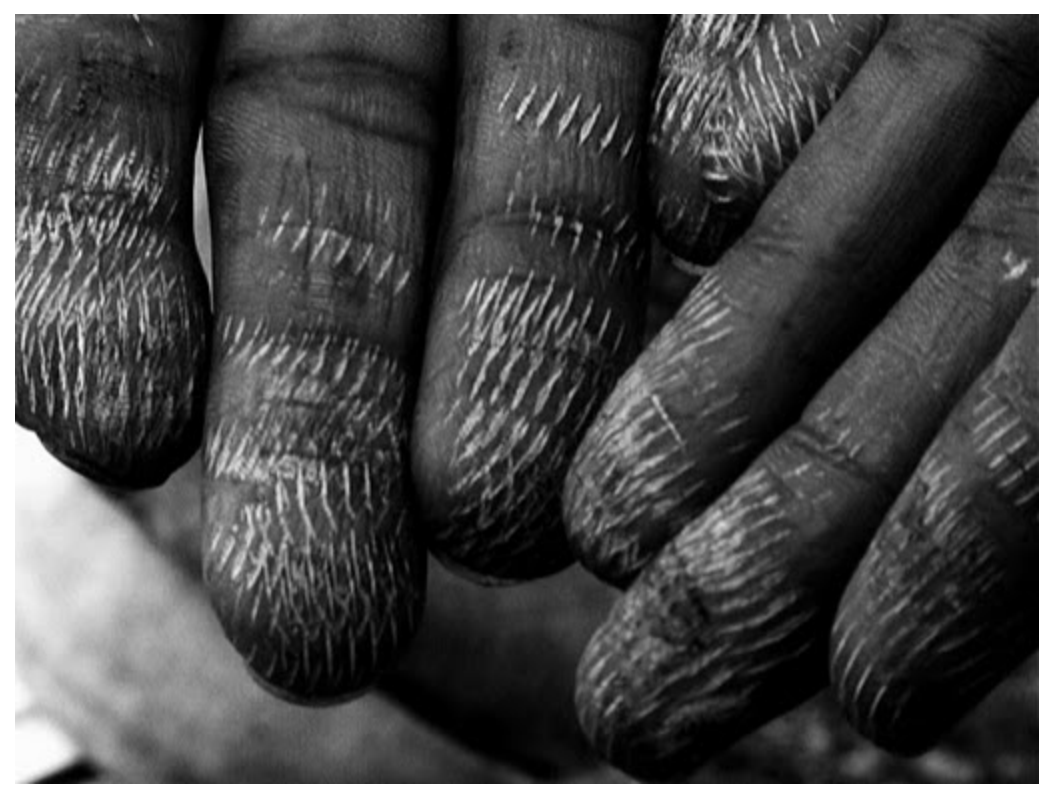

Fuente: Qu'ils reposent en révolte (Des figures de guerres I) de Sylvain George (France, 2011). 
Recibido para publicación en 10.01.2017 Aceptado para publicación en 12.06.2017 Received for publication in January 10 ${ }^{\text {th }}, 2017$ Accepted for publication in June $12^{\text {th }}, 2017$

ISSN impresso 1980-8585

ISSN eletrônico 2237-9843

http://dx.doi.org/10.1590/1980-85852503880005004 